\title{
Health and adverse childhood experiences among homeless youth
}

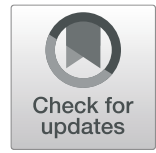

\author{
Andrew J. Barnes ${ }^{1 *}\left(\mathbb{D}\right.$, Amy L. Gower ${ }^{2}$, Mollika Sajady ${ }^{3}$ and Katherine A. Lingras ${ }^{4}$
}

\begin{abstract}
Background: Homelessness is associated with health problems and with adverse childhood experiences (ACEs). The risk of chronic health conditions for homeless compared to housed youth, and how this risk interacts with ACEs remains unclear. This study investigated the relationship between ACEs, housing, and child health, and whether: 1) ACEs and health vary by housing context; 2) ACEs and homelessness confer independent health risks; and 3) ACEs interact with housing with regard to adolescent health.

Methods: Using data from 119,254 8th-11th graders, we tested independent and joint effects of ACEs and pastyear housing status (housed, family homelessness, unaccompanied homelessness) on overall health and chronic health conditions, controlling for sociodemographic covariates.

Results: The prevalence of ACEs varied by housing status, with $34.1 \%$ of housed youth experiencing $\geq 1$ ACE vs. $56.3 \%$ of family-homeless and $85.5 \%$ of unaccompanied-homeless youth. Health status varied similarly. Homelessness and ACEs were independently associated with low overall health and chronic health conditions, after adjusting for covariates. Compared to housed youth, both family-homeless youth and unaccompanied-homeless youth had increased odds of low overall health and chronic physical and/or mental health conditions. All ACE $x$ housing-status interactions were significant (all $p<0.001$ ), such that ACE-related health risks were moderated by housing status.
\end{abstract}

Conclusions: ACEs and housing status independently predict health status during adolescence beyond other sociodemographic risks. Experiencing homelessness, whether unaccomapnied or with family, is associated with increased health risk, and every additional ACE increases this risk. Clinicians and health systems should advocate for policies that include stable housing as a protective factor.

Keywords: Developmental origins of health and disease, Adverse childhood experiences, Homelessness

\section{Background}

Adverse Childhood Experiences (ACEs) are common during childhood, with over 32 million youth (45\%) under 17 years having experienced at least one ACE in the United States [1]. Almost all youth with one or more

\footnotetext{
*Correspondence: drbarnes@umn.edu

'Developmental-Behavioral Pediatrics, Division of Clinical Behavioral

Neuroscience, Department of Pediatrics, University of Minnesota, Minneapolis, MN, USA

Full list of author information is available at the end of the article
}

ACEs report experiencing these stressful events before the age of 14 years [2]. Youth who experience homelessness have particularly high rates of ACEs and related cumulative psychosocial risk [3, 4]. However, research that compares the prevalence of ACEs between homeless and housed populations of youth is lacking.

The health consequences of ACEs are well-established in adults [5-9], and increasing evidence suggests that these pernicious effects often emerge during childhood and adolescence. Chronic health conditions that emerge during childhood in the context of ACEs occur along a risk gradient, with each additional ACE conferring

(C) The Author(s). 2021 Open Access This article is licensed under a Creative Commons Attribution 4.0 International License, which permits use, sharing, adaptation, distribution and reproduction in any medium or format, as long as you give appropriate credit to the original author(s) and the source, provide a link to the Creative Commons licence, and indicate if changes were made. The images or other third party material in this article are included in the article's Creative Commons licence, unless indicated otherwise in a credit line to the material. If material is not included in the article's Creative Commons licence and your intended use is not permitted by statutory regulation or exceeds the permitted use, you will need to obtain permission directly from the copyright holder. To view a copy of this licence, visit http://creativecommons.org/licenses/by/4.0/ The Creative Commons Public Domain Dedication waiver (http://creativecommons.org/publicdomain/zero/1.0/) applies to the data made available in this article, unless otherwise stated in a credit line to the data. 
additional risk [10-12]. For example, adolescents with ACEs are most likely to report poor overall health and are up to 1.5 times more likely to have obesity compared to peers without ACEs $[13,14]$. Another recent study of adolescents involved in the juvenile justice system found that youth with four or more ACEs experienced significant mental health symptoms; these symptoms were buffered by high levels of internal resilience, school connectedness, family communication, and peer role models [15].

The known associations between youth homelessness and stressors such as ACEs are especially notable given the high prevalence of youth homelessness; on a single night in 2018, at least 180,000 families with children and 36,000 unaccompanied youth in the United States experienced homelessness [16]. Likewise, public schools identified over 1.3 million homeless youth in 2016 (91\% of whom were homeless with family) - an increase of $4 \%$ over 2 years [17]. Youth experiencing family homelessness report more mental health problems than housed youth [18], including suicide attempts [19], even when controlling for family income. In addition, youth experiencing unaccompanied homelessness are at high risk of victimization, substance abuse, infectious diseases, and mental health problems [20]. While factors such as positive parenting relationships and increased parent responsiveness can moderate trauma symptoms and emotionalbehavioral concerns in children experiencing homelessness $[19,21]$, it remains unclear how housing contexts might be associated with health among youth at high psychosocial risk due to ACEs.

There are no studies that we are aware of that have compared the risk of chronic health conditions among homeless and housed youth in the context of ACEs. We aimed to investigate how ACEs and housing relate to child health by determining whether ACEs and child health vary by housing context; if ACEs and homelessness confer independent risks to health; and how ACEs interact with housing contexts vis a vis adolescent health. We hypothesized that youth experiencing unaccompanied homelessness would have more chronic health conditions and ACEs compared to those who are homeless with family; ACEs and homelessness would be independently associated with chronic health conditions in youth; and that health problems would increase with each additional ACE but that this risk gradient would be moderated by consistent housing.

\section{Methods}

\section{Study design and subjects}

Data come from the 2016 Minnesota Student Survey (MSS), a cross-sectional state-wide surveillance survey of youth health, risk, and protective factors offered triennially to every public and charter school serving 5th, 8th, 9th, and 11th grades in Minnesota. In keeping with state law, passive parental consent is used ( $<1 \%$ opt-out rate) and schools administer the survey via paper and pencil survey or online, at their discretion (the proportion of participants using each mode is not available). Approximately $2 \%$ of completed surveys are discarded due to highly implausible or incomplete data. In 2016, $85 \%$ of school districts contributed data from at least one grade. Because some items necessary for the current analysis were not asked of 5th graders, the current study uses data from 119,254 students in 8th, 9th, and 11th grade. The University of Minnesota Institutional Review Board determined this secondary analysis of anonymous data did not meet the definition of human subject research and was therefore exempt from further ethical review and approval.

\section{Measures}

\section{Adverse childhood experiences}

A total of eight yes/no items were used to assess the presence of six ACEs: psychological abuse (1 item), physical abuse (1 item), sexual abuse (2 items), familial substance abuse (2 items), domestic violence (1 item), and parental incarceration (1 item). Full details are described elsewhere [13]. In brief, for each ACE with two items, endorsement of either item was considered to indicate the presence of that ACE [22]. A count of the number of ACEs was calculated, creating an index representing 0 to 6 possible ACEs.

\section{Homelessness}

One item assessed with three response options assessed housing status: "During the past 12 months, have you stayed in a shelter, somewhere not intended as a place to live, or someone else's home because you had no other place to stay?" Response options included no; yes, with my parents or an adult family member; and yes, on my own without any adult family members. Responses were recoded to indicate 1) no past year homelessness; 2) past year homelessness with family only; 3 ) past year homeless alone, regardless of homeless with family response. Both for parsimonious interpretability of results and because experiencing both family- and non-familyhomelessness in the past year likely represents a level of housing instability that supercedes family homelessness, we decided, a priori, to include the 228 students who experienced both forms of homelessness in the homelessalone category.

\section{Health}

Students self-reported their overall health as excellent, very good, good, fair, or poor, which was dichotomized into excellent/very good compared to good/fair/poor $[23,24]$. Two questions assessed chronic health 
problems. Students reported the presence or absence of 1) "physical disabilities or long term-health problems (such as asthma, cancer, diabetes, epilepsy, or something else)?" or 2) "long-term mental health, behavioral, or emotional problems?" For both questions, long-term was defined as "lasting 6 months or more." Responses were combined to create four mutually exclusive groups: no chronic health problems, only chronic physical health problems, only chronic mental health problems, and both types of chronic health problems.

Sociodemographic covariates Additionally, we measured multiple sociodemographic variables with wellestablished associations with ACEs, housing status, and/ or health [25-27]. Students reported their sex (male/female) and grade (8th, 9th, or 11th). Two questions were combined to create race/ethnicity groups: Hispanic and Non-Hispanic White; Black/African/African American; Asian/Pacific Islander; American Indian; and multiracial. We included receipt of free or reduced-price lunch at school as a binary marker for low-income status. Finally, we created a binary variable for location (MinneapolisSt. Paul metropolitan area versus all other nonmetropolitan areas of Minnesota).

\section{Statistical analysis}

Descriptive statistics were computed to describe the sample, stratified by housing status to show the distribution of sociodemographic subgroups and ACEs across the three categories of housing. Chi-square tests evaluated bivariate associations between housing status and both overall health and chronic health problems, after ensuring assumptions for Chi-square tests were met (i.e., mutually exclusive categories, independent samples, no cell with an expected value of $<1$, and expected value of $\geq 5$ for at least $80 \%$ of cells), to determine variable selection for two multivariable analyses. First, we evaluated the simultaneous, independent effects of housing status and ACEs on health using logistic regression. Housing status was dummy coded to examine the effects of homelessness with family and homeless alone, compared to the reference group of youth with consistent housing. Second, the interaction between ACEs and housing status was added to the regression to assess moderation. Because all interactions were significant, the sample was stratified by housing status, and multifactor ANOVAs were conducted to probe moderation effects [28]. Although ANOVA and other linear models were designed for normally distributed variables, they have been shown to be valid approaches for analysis of large datasets $(n>$ 1000), regardless of the distribution. This approach allowed us to compare all three housing status groups to one another, rather than relying on comparisons to a control group. Adjusted predicted means are interpreted as predicted prevalence estimates for each group. All multivariable regressions controlled for sex, grade, race/ ethnicity, free/reduced price lunch, and metropolitan location. Given the very large sample size, missing data were excluded listwise. Alpha was set to 0.05 for all analyses, and IBM SPSS v25 was used for data analysis.

\section{Results}

\section{Prevalence of ACEs and health problems}

The sample is described in Table 1; missing data ranged from $0 \%$ (biological sex) to $6.0 \%$ (ACEs). Participants were roughly evenly split by sex and grade, and race/ethnicity distributions were consistent with the demographics of Minnesota youth. The distribution of ACEs varied by housing status, with a flatter and higher-prevalence distribution for youth who were homeless alone than for youth who were homeless with family, and a lessprevalent skew among those with consistent housing. The median number of ACEs was 0 for housed youth (interquartile range $(\mathrm{IQR})=1$ ); 1 for youth were homeless with family $(\mathrm{IQR}=2)$; and 2 for youth who were homeless alone $(\mathrm{IQR}=3)$. The prevalence of health problems also varied by housing status (Table 2). For all but chronic physical health problems, consistentlyhoused youth reported the best health in unadjusted analyses; those who were homeless with family reported intermediate levels of health problems; and students who were homeless alone had the highest frequency of health problems.

\section{Associations between ACEs, homelessness, and health}

Housing status and ACEs independently contributed to overall health and chronic health problems in multivariable logistic regressions examining independent effects of housing status and ACEs on health, controlling for sex, grade, race/ethnicity, free/reduced price lunch, and school metropolitan location (Table 3). Students who were homeless alone had higher adjusted odds of chronic mental health problems, and co-occurring chronic mental and physical health problems, than youth with consistent housing.

\section{Moderation of health Risk of ACEs by housing status}

Health risks increased by ACEs regardless of housing status (Figs. 1, 2, 3 and 4). Because statistical interactions between ACEs and housing were significant for all health outcomes, we probed how housing status moderated the associations between ACEs and health. For youth with 0-5 ACEs, consistent housing and family homelessness were associated with lower prevalence of co-occurring chronic physical and mental health problems (Fig. 1) and lower prevalence of mental health problems (Fig. 2) compared to their prevalence among youth who were homeless alone. For youth with 0-2 
Table 1 Sample Characteristics by Housing Status

\begin{tabular}{|c|c|c|c|}
\hline & $\begin{array}{l}\text { Housed } \\
n=112,750(94.5 \%)\end{array}$ & $\begin{array}{l}\text { Family Homeless } \\
n=5273(4.4 \%)\end{array}$ & $\begin{array}{l}\text { Unaccompanied Homeless } \\
n=1231(1.0 \%)\end{array}$ \\
\hline \multicolumn{4}{|l|}{ Sex } \\
\hline Male & $55,466(49.3 \%)$ & $2883(54.9 \%)$ & $705(57.7 \%)$ \\
\hline Female & $57,043(50.7 \%)$ & $2364(45.1 \%)$ & $516(42.3 \%)$ \\
\hline \multicolumn{4}{|l|}{ Grade } \\
\hline 8th & 39,643 (35.2\%) & $2530(48.0 \%)$ & $371(30.1 \%)$ \\
\hline 9th & 40,191 (35.6\%) & $1876(35.6 \%)$ & $391(31.8 \%)$ \\
\hline 11th & 32,916 (29.2\%) & 867 (16.4\%) & $469(38.1 \%)$ \\
\hline Free/reduced lunch & 28,970 (25.9\%) & 2605 (49.9\%) & $583(47.7 \%)$ \\
\hline Metro & $59,636(52.9 \%)$ & $2726(51.7 \%)$ & $599(48.7 \%)$ \\
\hline \multicolumn{4}{|l|}{ Race/ethnicity } \\
\hline $\mathrm{NH}$ American Indian & $1210(1.1 \%)$ & 137 (2.6\%) & $51(4.2 \%)$ \\
\hline NH Asian/Pacific Isl. & $6409(5.7 \%)$ & $601(11.5 \%)$ & $57(4.7 \%)$ \\
\hline NH Black & $5988(5.3 \%)$ & $460(8.8 \%)$ & $93(7.7 \%)$ \\
\hline NH Multiracial & $8090(7.2 \%)$ & $485(9.3 \%)$ & $170(14.0 \%)$ \\
\hline Hispanic & 10,013 (8.9\%) & 779 (14.9\%) & $164(13.5 \%)$ \\
\hline NH White & 80,306 (71.7\%) & 2765 (52.9\%) & $679(55.9 \%)$ \\
\hline \multicolumn{4}{|l|}{ ACEs } \\
\hline 0 ACEs & 74,002 (65.9\%) & $2287(43.7 \%)$ & $177(14.5 \%)$ \\
\hline $1 \mathrm{ACE}$ & 21,315 (19.0\%) & $1173(22.4 \%)$ & $244(20.0 \%)$ \\
\hline 2 ACEs & $9408(8.4 \%)$ & 719 (13.7\%) & $193(15.8 \%)$ \\
\hline 3 ACEs & $4545(4.0 \%)$ & 509 (9.7\%) & $205(16.8 \%)$ \\
\hline 4 ACEs & $2057(1.8 \%)$ & $303(5.8 \%)$ & $178(14.6 \%)$ \\
\hline 5 ACEs & $894(0.8 \%)$ & $172(3.3 \%)$ & $161(13.2 \%)$ \\
\hline 6 ACEs & $152(0.1 \%)$ & $67(1.3 \%)$ & $62(5.1 \%)$ \\
\hline
\end{tabular}

ACE Adverse Childhood Experience, NH Non-Hispanic

or $>4$ ACEs, physical health did not differ by housing status, but among those with 3-4 ACEs, consistent housing was associated with lower prevalence of physical health problems than family homelessness (Fig. 3). For youth with $<2$ ACEs, consistent housing was associated with the highest levels of overall health (Fig. 4).

\section{Discussion}

This study documents differential health risks among youth who were homeless with or without a family member (i.e., unaccompanied) during the past year in the context of ACEs. Youth experiencing homelessness were more likely to have health problems, ranging from $10 \%$ increased odds of physical health conditions among

Table 2 Chi-Square Test of Associations between Overall Health and Chronic Health Problems by Housing Status

\begin{tabular}{llll}
\hline & Housed & Family Homeless & Unaccompanied Homeless \\
\hline Chronic Health Status* & & & $490(40.4 \%)$ \\
No Chronic Problems & $81,060(72.6 \%)$ & $3341(64.2 \%)$ & $352(29.0 \%)$ \\
Chronic Mental Health & $13,592(12.2 \%)$ & $871(16.7 \%)$ & $118(9.7 \%)$ \\
Chronic Physical Health & $11,648(10.4 \%)$ & $563(10.8 \%)$ & $253(20.9 \%)$ \\
Both Chronic Problems & $5384(4.8 \%)$ & $433(8.3 \%)$ & $686(56.0 \%)$ \\
Overall Health* & & & $539(44.0 \%)$ \\
Good/Fair/Poor & $35,649(31.7 \%)$ & $3009(57.3 \%)$ & \\
Excellent/Nery Good & $76,817(68.3 \%)$ & & \\
\hline
\end{tabular}

*Chi square test of association indicated significant differences between groups, $p<0.05$ 
Table 3 Logistic Regressions Predicting Health Problems based on Homeless Status and ACEs

\begin{tabular}{lllll}
\hline & Good/Fair/Poor Overall Health & $\begin{array}{l}\text { Chronic Physical Health vs. } \\
\text { No Chronic Problems }\end{array}$ & $\begin{array}{l}\text { Chronic Mental Health vs. } \\
\text { No Chronic Problems }\end{array}$ & $\begin{array}{l}\text { Chronic Both } \\
\text { vs. } \\
\text { No Chronic Problems }\end{array}$ \\
\hline Housed & 1.00 & 1.00 & 1.00 & 1.00 \\
Family Homeless & $1.19(1.12,1.27)$ & $1.11(1.02,1.23)$ & $1.28(1.17,1.39)$ & $1.44(1.28,1.62)$ \\
Unaccompanied Homeless & $1.34(1.18,1.51)$ & $1.35(1.09,1.67)$ & $2.03(1.73,2.38)$ & $2.48(2.48,3.58)$ \\
ACEs count & $1.40(1.38,1.41)$ & $1.16(1.14,1.18)$ & $1.65(1.63,1.68)$ & $1.74(1.70,1.78)$ \\
\hline
\end{tabular}

Analyses controlled for sex, grade, race/ethnicity, free/reduced price lunch qualification, and metropolitan location. Results presented are adjusted odds ratios with $95 \%$ confidence intervals; all were significant at $p<0.05$

youth who were homeless with a family member, to over 2 times the odds of co-occurring chronic physical and mental conditions among unaccompanied-homeless youth. Cumulative psychosocial risk was much higher among these youth compared to those with consistent housing - a majority of youth who were homeless with a family member had 1 or more ACEs, and nearly 1 in 5 of youth who were homeless unaccompanied had over 4 ACEs. Each additional ACE, regardless of housing status, increased the odds of low overall health by $40 \%$; chronic physical health conditions by $16 \%$; chronic mental health conditions by $65 \%$; and both chronic mental and physical health conditions by $74 \%$. However, the health risks of homelessness remained elevated to a similar degree to the risks of ACEs even after controlling for ACEs along with sociodemographic factors that are associated with both homelessness and health. Furthermore, past-year homelessness compounded the health risks of ACEs to varying magnitudes depending upon past-year housing context (consistently-housed vs. homeless with or without family) and broad category of health outcome (overall health vs. chronic physical and/or mental health).

The finding that homelessness is associated with health problems is consistent with prior research [29, 30], and is the first to our knowledge to directly compare health between youth who were consistently housed and those who were homeless in the past year with family or unaccompanied. Similarly, the finding that health problems during adolescence are more prevalent with increasing ACEs aligns with research on pediatric obesity, behavioral health, and substance abuse [13, 31], as does the finding that health problems are associated with negative life events among young children experiencing concurrent family homelessness [4, 32, 33]. Our findings build upon this prior knowledge by establishing that ACEs and housing status pose independent and interacting problems for children's health. Since health problems partially mediate long-term homelessness for adults who had ACEs [34, 35], our results imply that more intensive prevention, identification, and intensive treatment of chronic health problems in youth experiencing homelessness and ACEs could help "break the cycle" of homelessness across the lifespan.

Our results also highlight the complex interactions between housing, health, and ACEs. Few studies to date have examined risk gradients among subtypes of youth homelessness within the same sample. While we found that being homeless with family is associated with health risks, we also found that these youth may be somewhat better off from a health perspective than

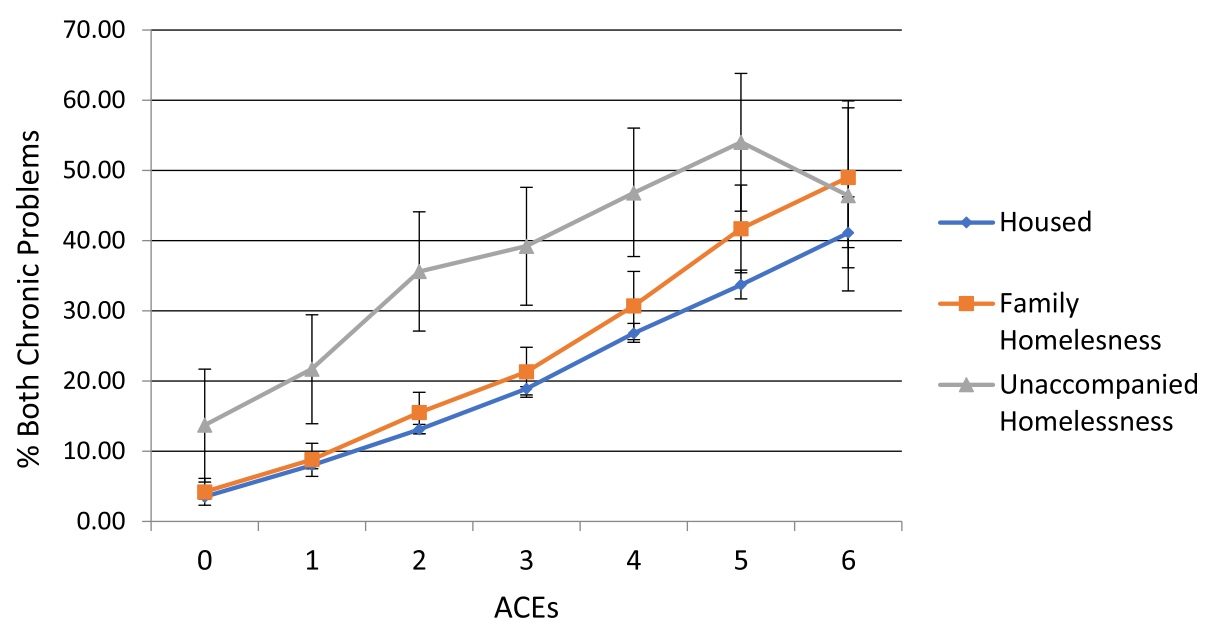

Fig. 1 Prevalence of Chronic Physical and Mental Health Problems by ACEs and Housing Status 


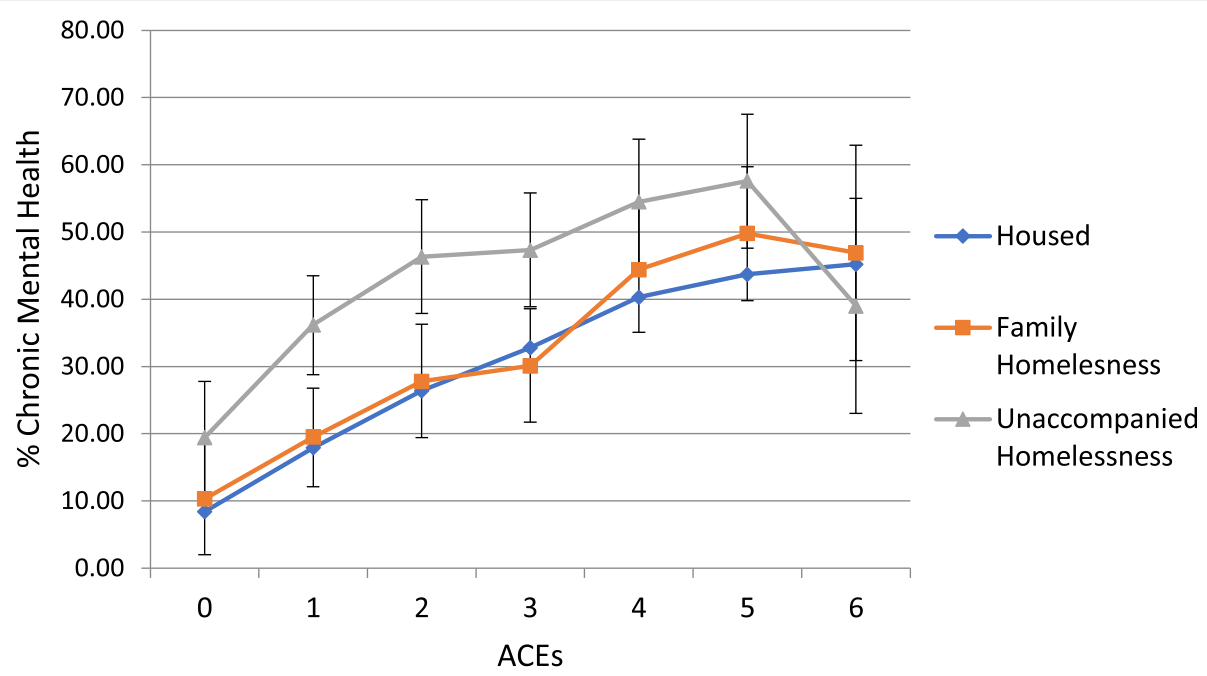

Fig. 2 Prevalence of Chronic Mental Health Problems by ACEs and Housing Status

unaccompanied-homeless youth, and that youth with ACEs and unaccompanied homelessness have a very high prevalence of co-occurring health conditions. These results are consistent with a recent study of the intersection between youth who ran away from home and those who experienced homeless, showing that those who had both run away and been homeless were at greater odds of mental health problems than either group alone (those who ran away had intermediate odds) [36]. Overall, our findings affirm the protective nature of caregivers and families [37-41] and underscore the importance of ensuring that youth who have suffered adversity (e.g., maltreatment, neglect, or family dysfunction) are protected from becoming separated from supportive family members when faced with evictions or unsafe housing, humanitarian crises, disasters, war, or refugee/immigration policies that simultaneously threaten the integrity of families and the homes that allow health to thrive.

The strengths of this study include its use of a large, representative statewide sample, increasing statistical power to test hypothesized interactions between psychosocial factors among hard-to-reach populations of youth (i.e., those with high ACEs and/or homelessness).

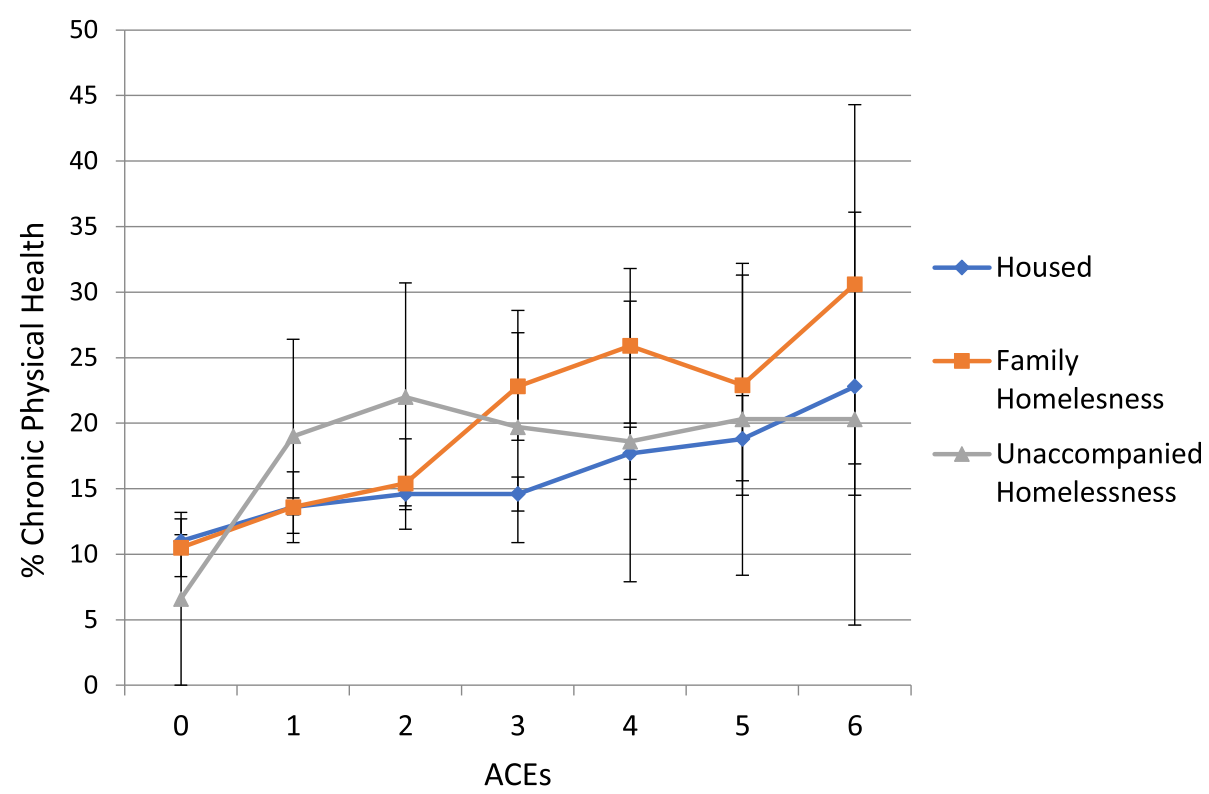

Fig. 3 Prevalence of Chronic Physical Health Problems by ACEs and Housing Status 


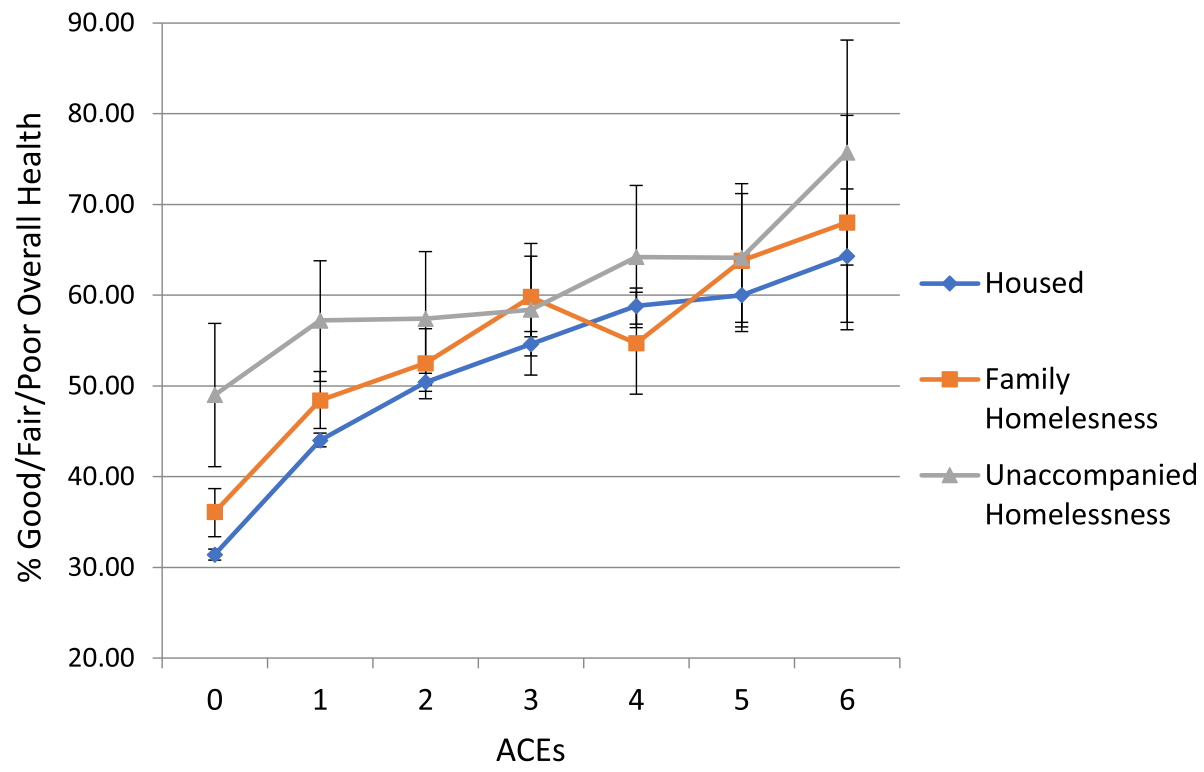

Fig. 4 Prevalence of Good/Fair/Poor Health by ACEs and Housing Status

Additionally, the fact that these youth are enrolled and attending school provides one clear route for providing services and support. Limitations include the inability to draw causal inferences due to the cross-sectional sample; for example, health problems may increase the chances that youth experience homelessness. Furthermore, although MSS items assessing health and housing status have established associations with various outcomes in other studies [19, 42], these items are self-reported and have not yet been assessed for reliability and external validity. In particular, the validity of self-reported health status may be influenced by the number of chronic health conditions that are presented to respondents in health surveys [43]. Similarly, the housing items in the MSS do not assess other aspects of housing such as duration or frequency of homelessness, rent instability, or housing safety. Nevertheless, assessing homelessness using a broad definition, as done with the MSS, may be more accurate than head counts [44-46]. Similarly, the MSS sample selects for youth who attend school, so while it gives voice to many youth who are traditionally excluded from public health research (such as those experiencing homelessness), some of these youth who are most at risk (e.g., high ACEs; living on the street) might also be those most likely to be absent from school at the time of survey administration [47]. Given that our cohort was confined to one state (and reporting on only one year of housing status), longitudinal research of national samples is needed to better ascertain the directionality and generalizability of interactions between life experiences and health (e.g., before, during, and after episodes of homelessness). We are also limited to questions asked on the Minnesota Student Survey, limiting the covariates we could include in our models that have been associated with ACEs and/or mental health, such as juvenile criminal offending [48]. The administration mode (paper vs. online) of the MSS could also not be factored into our analyses. Finally, some of the stratified logistic regression models examining moderation of health by housing status had small sample sizes for youth with high ACEs, increasing the chances of type II errors (failing to reject false null hypotheses). We thus recommend that longitudinal nationally-representative surveys of youth health include items on both housing context and ACEs to inform program and policy development more precisely.

Our results have important clinical and policy implications for youth at high risk due to histories of maltreatment, neglect, and family dysfunction. Few pediatric clinicians ask about ACEs or document childhood adversity in the medical record [49]. Notably, ACEs surveys do not typically include housing status, so even if ACEs surveillance became a routine part of pediatric or community healthcare, housing experiences and/or needs might not be considered without additional screening. While some clinical systems have piloted methods to screen for social determinants of health, including housing and ACEs, efforts are widely variable and lack consistent protocols across the field [50-53]. As such efforts advance, our results - and those of others showing that even unstable or precarious housing is associated with health risks for children $[54,55]$ - suggest that the context of housing will be important to specify (i.e., within social determinants of health screening protocols that 
may include ACEs) because it is differentially associated with health risks.

Additionally, clinicians cite being hesitant to ask about some psychosocial topics due to lack of training in these areas as well as uncertainty as to how to resolve issues that arise from these questions [56, 57]. For example, within typical primary care settings, social work staff may be unavailable or overwhelmed, limited options may be available for on-site mental health care and related supports, and community-based options such as housing advocacy may not exist. Increasingly, efforts to link services such as behavioral health, food banks, housing services, and medical-legal partnerships within pediatric primary care attempt to bridge these gaps. Increased public support for such linkages and crosssector collaborations such as school mental health and school-based clinics, along with public-private partnerships, will be essential in helping pediatric health care organizations integrate housing and ACEs screening, surveillance, and remediation into their processes that aim to address these and other social determinants of health.

In addition to trauma-informed care, advocacy is needed for "resilience-informed care" that incorporates protective factors both in clinical practice and social policies $[41,58]$. Traditionally, policy work and medical care are focused on identifying and treating problems. Less attention is paid to what is going well, particularly in contexts of known risk, such as homelessness or ACEs. For instance, our results identify important nuances in health within the context of homelessness (i.e. level of ACEs and unaccompanied homeless versus homeless with family). These results illuminate that even within challenging situations, efforts to keep families together and ameliorate toxic stress can have important impacts on child health. Policies should aim to reflect this and recognize the protective impact of family relationships as well as other known facilitators of resilience.

\section{Conclusion}

Youth experiencing ACEs or homelessness are at risk of poor overall health and chronic health conditions. Consistent housing in the past year has a generally protective effect on physical and mental health and can buffer the impact of ACEs during adolescence. Potential solutions include preventing ACEs through policy and public awareness; providing of trauma- and resilience-informed health and psychosocial services; and policies that support stable and sustainable family housing. Surveillance of ACEs at a community level (e.g., at the level of school districts, where data on homeless and highly mobile students is also kept) could be one approach to identifying which schools or student populations could benefit from targeted housing and health supports.

\section{Abbreviations}

ACE: Adverse Childhood Experience; AOR: Adjusted Odds Ratio;

Cl: Confidence Interval; SD: Standard Deviation; MSS: Minnesota Student Survey

\section{Acknowledgments \\ not applicable.}

Financial disclosure

All authors have no financial relationships relevant to this article to disclose.

Table of contents summary

Consistent housing is associated with lower risk of physical and emotional adolescent health problems in the context of ACEs.

\section{Authors' contributions}

$\mathrm{AB}$ conceptualized and designed the study, provided data interpretation, drafted the initial manuscript, and approved the final manuscript as submitted. AG conducted statistical analyses, drafted tables and figures, provided data interpretation, drafted the manuscript, and approved the final manuscript as submitted. MS provided data interpretation, drafted the manuscript, and approved the final manuscript as submitted. $K L$ provided literature review, data interpretation, drafted and critically reviewed the manuscript, and approved the final manuscript as submitted.

\section{Funding}

This study was supported by DHHS/MCHB grant \#T73MC12835. The second author's time was supported by cooperative agreement 5U48DP005022 ( $R$ Sieving, PI) from the Centers for Disease Control and Prevention, Prevention Research Center Program. The contents are solely the responsibility of the authors and do not necessarily represent the official views of the Centers for Disease Control and Prevention or the Department of Health and Human Services.

\section{Availability of data and materials}

The data that support the findings of this study are available from the Minnesota Department of Education, but restrictions apply to the availability of these data, which were used under license for the current study, and so are not publicly available. Data are however available from the authors upon reasonable request and with permission of the Minnesota Department of Education.

\section{Declarations}

Ethics approval and consent to participate

The University of Minnesota Institutional Review Board determined this secondary analysis of anonymous data did not meet the definition of human subject research (\#20150608).

\section{Consent for publication}

not applicable.

\section{Competing interests}

The authors declare that they have no competing interests.

\section{Author details}

${ }^{1}$ Developmental-Behavioral Pediatrics, Division of Clinical Behavioral Neuroscience, Department of Pediatrics, University of Minnesota, Minneapolis, MN, USA. ²Department of Pediatrics, University of Minnesota Medical School, 717 Delaware Street SE, Minneapolis, MN 55414, USA. ${ }^{3}$ Children's Minnesota Developmental Pediatrics, 2530 Chicago Ave S STE G055, Minneapolis, MN 55404, USA. ${ }^{4}$ Department of Psychiatry and Behavioral Sciences, University of Minnesota, Minneapolis, MN, USA.

Received: 18 February 2020 Accepted: 21 March 2021

Published online: 07 April 2021

\section{References}

1. Data Resource Center for Child and Adolescent Health supported by the U. S. Department of Health and Human Services Health Resources and Services Administration. Child and Adolescent Health Measurement Initiative. 
National Survey of Children's Health, 2016-2017. http://childhealthdata.org/ browse/survey/results?q=5545\& $r=1$. Accessed June 20, 2019.

2. Flaherty EG, Thompson R, Dubowitz H, Harvey EM, English DJ, Proctor LJ, et al. Adverse childhood experiences and child health in early adolescence. JAMA Pediatr. 2013;167(7):622-9. https://doi.org/10.1001/jamapediatrics.2 013.22.

3. Masten AS, Miliotis D, Graham-Bermann SA, Ramirez M, Neemann J. Children in homeless families: risks to mental health and development. J Consult Clin Psychol. 1993;61(2):335-43. https://doi.org/10.1037/0022-006X. 61.2.335.

4. Narayan AJ, Nerenberg LS, Kalstabakken AW, Labella MH, Monn AR, Masten AS. Intergenerational continuity of adverse childhood experiences in homeless families: unpacking exposure to maltreatment versus family dysfunction. Am J Orthop. 2017;87(1):3-14. https://doi.org/10.1037/ ort0000133.

5. Felitti VJ, Anda RF, Nordenberg D, et al. Relationship of childhood abuse and household dysfunction to many of the leading causes of death in adults. The adverse childhood experiences (ACE) study. Am J Prev Med. 1998;14(4):245-58. https://doi.org/10.1016/S0749-3797(98)00017-8.

6. Campbell JA, Walker RJ, Egede LE. Associations between adverse childhood experiences, high-risk behaviors, and morbidity in adulthood. Am J Prev Med. 2016;50(3):344-52. https://doi.org/10.1016/j.amepre.2015.07.022.

7. Wade R, Cronholm PF, Fein JA, et al. Household and community-level adverse childhood experiences and adult health outcomes in a diverse urban population. Child Abus Negl. 2016;52:135-45. https://doi.org/10.1016/ j.chiabu.2015.11.021.

8. Herzog Jl, Schmahl C. Adverse childhood experiences and the consequences on neurobiological, psychosocial, and somatic conditions across the lifespan. Front Psychiatry. 2018;9. https://doi.org/10.3389/fpsyt.201 8.00420 .

9. Morris G, Berk M, Maes M, Carvalho AF, Puri BK. Socioeconomic deprivation, adverse childhood experiences and medical disorders in adulthood: mechanisms and associations. Mol Neurobiol. 2019;56(8):5866-90. https:// doi.org/10.1007/s12035-019-1498-1.

10. Burke NJ, Hellman JL, Scott BG, Weems CF, Carrion VG. The impact of adverse childhood experiences on an urban pediatric population. Child Abuse Negl. 2011;35(6):408-13. https://doi.org/10.1016/j.chiabu.2011.02.006.

11. Danese A, McEwen BS. Adverse childhood experiences, allostasis, allostatic load, and age-related disease. Physiol Behav. 2012;106(1):29-39. https://doi. org/10.1016/j.physbeh.2011.08.019.

12. Oh DL, Jerman P, Silvério Marques S, Koita K, Purewal Boparai SK, Burke Harris N, et al. Systematic review of pediatric health outcomes associated with childhood adversity. BMC Pediatr. 2018;18(1):83. https://doi.org/10.11 86/s12887-018-1037-7.

13. Davis L, Barnes AJ, Gross AC, Ryder JR, Shlafer RJ. Adverse childhood experiences and weight status among adolescents. J Pediatr. 2019;204:7176.e1. https://doi.org/10.1016/j.jpeds.2018.08.071.

14. Bellis MA, Hughes K, Ford K, Hardcastle KA, Sharp CA, Wood S, et al. Adverse childhood experiences and sources of childhood resilience: a retrospective study of their combined relationships with child health and educational attendance. BMC Public Health. 2018;18(1):792. https://doi.org/10.1186/s12 889-018-5699-8.

15. Clements-Nolle K, Waddington R. Adverse childhood experiences and psychological distress in juvenile offenders: the protective influence of resilience and youth assets. J Adolesc Health. 2019;64(1):49-55. https://doi. org/10.1016/j.jadohealth.2018.09.025.

16. Henry M, Mahathey A, Morrill T, et al. The 2018 Annual Homeless Assessment Report (AHAR) to Congress; Part 1: Point-in-time estimates of homelessness. https://www.hudexchange.info/resources/documents/2018-A HAR-Part-1.pdf. Accessed June 20, 2019.

17. National Center for Homeless Education. Federal Data Summary School Years 2013-2014 to 2015-2016, Education for Homeless Children and Youth. https://www2.ed.gov/programs/homeless/federal-data-summary.pdf. Published 2017. Accessed June 20, 2019.

18. Bassuk EL, Richard MK, Tsertsvadze A. The prevalence of mental illness in homeless children: a systematic review and meta-analysis. J Am Acad Child Adolesc Psychiatry. 2015;54(2):86-96.e2. https://doi.org/10.1016/j.jaac.2 014.11.008.

19. Barnes AJ, Gilbertson J, Chatterjee D. Emotional health among youth experiencing family homelessness. Pediatrics. 2018;141(4). https://doi.org/1 0.1542/peds.2017-1767.
20. Davies BR, Allen NB. Trauma and homelessness in youth: psychopathology and intervention. Clin Psychol Rev. 2017;54:17-28. https://doi.org/10.1016/j. cpr.2017.03.005.

21. Herbers JE, Cutuli JJ, Supkoff LM, Narayan AJ, Masten AS. Parenting and coregulation: adaptive systems for competence in children experiencing homelessness. Am J Orthop. 2014;84:420-30 http://psycnet.apa.orgjournals/ ort/84/4/420. Accessed February 19, 2016.

22. Dong M, Anda RF, Felitti VJ, Dube SR, Williamson DF, Thompson TJ, et al. The interrelatedness of multiple forms of childhood abuse, neglect, and household dysfunction. Child Abus Negl. 2004;28(7):771-84. https://doi. org/10.1016/j.chiabu.2004.01.008.

23. de Bruin A, Picavet HS, Nossikov A. Common instruments for health for all indicators. In: Health Interview Surveys. Towards International Harmonization of Methods and Instruments. Geneva; 1996. p. 51-2. https://doi.org/10.1016/ s0277-9536(97)84078-6.

24. DeSalvo KB, Bloser N, Reynolds K, He J, Muntner P. Mortality prediction with a single general self-rated health question: a meta-analysis. J Gen Intern Med. 2006;20(3):267-75. https://doi.org/10.1111/j.1525-1497.2005.00291.x.

25. Van Dyck PC, Kogan MD, McPherson MG, Weissman GR, Newacheck PW. Prevalence and characteristics of children with special health care needs. Arch Pediatr Adolesc Med. 2004;158(9):884-90. https://doi.org/10.1001/a rchpedi.158.9.884.

26. Duke NN, Borowsky IW. Adverse childhood experiences: evidence for screening beyond preventive visits. Child Abus Negl. 2018;81(0):380-8. https://doi.org/10.1016/j.chiabu.2018.05.015.

27. Nilsson SF, Nordentoft M, Hjorthøj C. Individual-level predictors for becoming homeless and exiting homelessness: a systematic review and meta-analysis. J Urban Heal. 2019;96(5):741-50. https://doi.org/10.1007/s11 524-019-00377-x.

28. Lumley T, Diehr P, Emerson S, Chen L. The importance of the normality assumption in large public health data sets. Annu Rev Public Health. 2002; 23(1):151-69. https://doi.org/10.1146/annurev.publhealth.23.100901.140546.

29. Patterson ML, Moniruzzaman A, Somers JM. Setting the stage for chronic health problems: cumulative childhood adversity among homeless adults with mental illness in Vancouver, British Columbia. BMC Public Health. 2014; 14(1):350. https://doi.org/10.1186/1471-2458-14-350.

30. Kerker BD, Zhang J, Nadeem E, et al. Adverse Childhood Experiences and Mental Health, Chronic Medical Conditions, and Development in Young Children. Acad Pediatr. 2015;15(5). https://doi.org/10.1016/j.acap.2015.05.005.

31. Lucenko BA, Sharkova IV, Huber A, Jemelka R, Mancuso D. Childhood adversity and behavioral health outcomes for youth: an investigation using state administrative data. Child Abus Negl. 2015;47:48-58. https://doi.org/1 0.1016/j.chiabu.2015.07.006.

32. Barnes A, Lafavor T, Cutuli J, Zhang L, Oberg C, Masten A. Health and SelfRegulation among School-Age Children Experiencing Family Homelessness. Children. 2017;4(8). https://doi.org/10.3390/children4080070.

33. Cutuli JJ, Ahumada SM, Herbers JE, Lafavor TL, Masten AS, Oberg CN. Adversity and children experiencing family homelessness: implications for health. J Child Poverty. 2017;23(1):41-55. https://doi.org/10.1080/10796126.2 016.1198753.

34. Stein JA, Leslie MB, Nyamathi A. Relative contributions of parent substance use and childhood maltreatment to chronic homelessness, depression, and substance abuse problems among homeless women: mediating roles of self-esteem and abuse in adulthood. Child Abus Negl. 2002;26(10):1011-27. https://doi.org/10.1016/S0145-2134(02)00382-4.

35. Roos LE, Mota N, Afifi TO, Katz LY, Distasio J, Sareen J. Relationship between adverse childhood experiences and homelessness and the impact of Axis I and II disorders. Am J Public Health. 2013;103(Suppl 2):275-81. https://doi. org/10.2105/A.JPH.2013.301323.

36. Gewirtz O'Brien JR, Edinburgh LD, Barnes AJ, McRee AL. Mental health outcomes among homeless, runaway, and stably housed youth. Pediatrics. 2020;145(4). https://doi.org/10.1542/peds.2019-2674.

37. Rutter M. Resilience in the face of adversity. Br J Psychiatry. 1985;147(6):598611. https://doi.org/10.1192/bjp.147.6.598.

38. Gorman-Smith D, Henry DB, Tolan PH. Exposure to community violence and violence perpetration: the protective effects of family functioning. I Clin Child Adolesc Psychol. 2004;33(3):439-49. https://doi.org/10.1207/s15374424 jсcр3303_2.

39. Brown SM, Shillington AM. Childhood adversity and the risk of substance use and delinquency: the role of protective adult relationships. Child Abuse Negl. 2017;63:211-21. https://doi.org/10.1016/J.CHIABU.2016.11.006. 
40. Von Cheong E, Sinnott C, Dahly D, Kearney PM. Adverse childhood experiences (ACES) and later-life depression: perceived social support as a potential protective factor. BMJ Open. 2017;7(9):e013228. https://doi.org/1 0.1136/BMJOPEN-2016-013228.

41. Sege RD, Harper BC. Responding to ACEs with HOPE: health outcomes from positive experiences. Acad Pediatr. 2017;17(7):S79-85. https://doi.org/10.101 6/J.ACAP.2017.03.007.

42. Barnes AJ, Eisenberg ME, Resnick MD. Suicide and self-injury among children and youth with chronic health conditions. Pediatrics. 2010;125(5). https://doi.org/10.1542/peds.2009-1814.

43. Ramond-Roquin A, Haggerty J, Lambert M, Almirall J, Fortin M. Different multimorbidity measures result in varying estimated levels of physical quality of life in individuals with multimorbidity: a coss-sectional study in the general population. Biomed Res Int. 2016;2016:7845438-9. https://doi. org/10.1155/2016/7845438.

44. Cutuli JJ, Steinway C, Perlman S, Herbers JE, Eyrich-Garg KM, Willard J. Youth homelessness: prevalence and associations with weight in three geographies. Heal Soc Work. 2015;40(4):316-24. https://doi.org/10.1093/hsw/ hlv065.

45. Cutuli JJ. Homelessness in high school: population-representative rates of self-reported homelessness, resilience, and risk in Philadelphia. Soc Work Res. 2018:42(3):159-68. https://doi.org/10.1093/swr/svy013.

46. Jetelina KK, Reingle Gonzalez JM, Cuccaro PM, Peskin MF, Elliott MN, Coker $T R$, et al. The association between familial homelessness, aggression, and victimization among children. J Adolesc Health. 2016;59(6):688-95. https:// doi.org/10.1016/j.jadohealth.2016.07.014

47. Kearney CA. School absenteeism and school refusal behavior in youth: A contemporary review. https://doi.org/10.1016/..cpr.2007.07.012.

48. Delisi M, Alcala J, Kusow A, et al. Adverse childhood experiences, commitment offense, and race/ethnicity: Are the effects crime-, race-, and ethnicity-specific? Int J Environ Res Public Health. 2017;14(3). https://doi. org/10.3390/ijerph14030331.

49. Karatekin C, Almy B, Mason SM, Borowsky I, Barnes A. Documentation of child maltreatment in electronic health records. Clin Pediatr (Phila). 2017; 57(9):1041-52. https://doi.org/10.1177/0009922817743571.

50. Silverstein M, Conroy K, Sandel M. Screening for social determinants of health in pediatric primary care. Pediatr Ann. 2008;37(11):740-6. http://www. ncbi.nlm.nih.gov/pubmed/19024841. . https://doi.org/10.3928/00904481-2 0081101-11.

51. Garg A, Butz AM, Dworkin PH, Lewis RA, Serwint JR. Screening for basic social needs at a medical home for low-income children. Clin Pediatr (Phila). 2009;48(1):32-6. https://doi.org/10.1177/0009922808320602.

52. Oh DL, Jerman P, Purewal Boparai SK, Koita K, Briner S, Bucci M, et al. Review of tools for measuring exposure to adversity in children and adolescents. J Pediatr Heal Care. 2018;32(6):564-83. https://doi.org/10.1016/j. pedhc.2018.04.021

53. Barnes AJ, Anthony BJ, Karatekin C, Lingras KA, Mercado R, Thompson LA. Identifying adverse childhood experiences in pediatrics to prevent chronic health conditions. Pediatr Res. 2020;87(2):362-70. https://doi.org/10.1038/ s41390-019-0613-3.

54. Meyers A, Cutts D, Frank DA, Levenson S, Skalicky A, Heeren T, et al. Subsidized housing and Children's nutritional status. Arch Pediatr Adolesc Med. 2005;159(6):551-6. https://doi.org/10.1001/archpedi.159.6.551.

55. Sandel M, Sheward R, Ettinger de Cuba S, et al. Unstable Housing and Caregiver and Child Health in Renter Families. Pediatrics. 2018. https://doi. org/10.1542/peds.2017-2199.

56. Olson AL, Kemper KJ, Kelleher KJ, Hammond CS, Zuckerman BS, Dietrich AJ. Primary care pediatricians' roles and perceived responsibilities in the identification and Management of Maternal Depression. Pediatrics. 2002 110(6):1169-76. https://doi.org/10.1542/peds.110.6.1169.

57. Horwitz SM, Kelleher KJ, Stein REK, Storfer-Isser A, Youngstrom EA, Park ER, et al. Barriers to the identification and management of psychosocial issues in children and maternal depression. Pediatrics. 2007;119(1):e208-18. https:// doi.org/10.1542/peds.2005-1997.

58. Masten A, Barnes A. Resilience in children: developmental perspectives. Children. 2018;5(7):98. https://doi.org/10.3390/children5070098.

\section{Publisher's Note}

Springer Nature remains neutral with regard to jurisdictional claims in published maps and institutional affiliations.

Ready to submit your research? Choose BMC and benefit from:

- fast, convenient online submission

- thorough peer review by experienced researchers in your field

- rapid publication on acceptance

- support for research data, including large and complex data types

- gold Open Access which fosters wider collaboration and increased citations

- maximum visibility for your research: over $100 \mathrm{M}$ website views per year

At BMC, research is always in progress.

Learn more biomedcentral.com/submissions 